\title{
Breast cancer involvement of the nipple- areola complex and implications for nipple- sparing mastectomies: a retrospective observational study in 137 patients
}

Mohammed Faisal ${ }^{1 *}$ (D), Hamada Fathy ${ }^{1}$, Ahmed M. M. Gomaa ${ }^{1}$, Haidi Abd-Elzaher ${ }^{1}$, Mohamed A. H. Ahmed ${ }^{2}$ and Mohamed Gamal Sayed ${ }^{1}$

\begin{abstract}
Introduction: Nipple-sparing mastectomy (NSM) has gained much attention by enhancing the aesthetic outcome in breast carcinoma patients. The aim of this study was to assess the prevalence of malignant affection of the nippleareola complex (NAC) in breast carcinoma patients and its correlation with prognostic factors for breast cancer.

Patients and methods: This study included 137 female patients diagnosed with breast carcinoma at different disease stages who were admitted to our surgical oncology unit at Suez Canal University Hospital from June 15, 2014 to January 25, 2017. We excluded patients with evidence of nipple involvement as ulceration or patients with previous breast surgery with periareolar incisions. This study was designed to test the hypothesis that the NAC can be spared in certain selected patients. All studied participants provided a full history and underwent general and local clinical examinations, pre-operative laboratory tests, and radiological and pathological evaluations.

Results: The mean age of the study population was $47.39 \pm 8.01$ years. Among the patients, the NAC was affected in $12(11.40 \%)$ patients. Patients with NAC involvement showed a significantly larger tumor size of more than $4 \mathrm{~cm}$ and a shorter tumor-nipple distance of less than $2 \mathrm{~cm}(p=0.000)$. Lymph node metastasis was associated with NAC involvement $(p=0.001)$, with increased risk when more than 10 lymph nodes were involved $(p=0.007)$.

Lymphovascular invasion was a significant predictor of NAC involvement $(p=0.014)$. Multifocal as well as multicentric tumors were significantly associated with NAC involvement ( $p=0.016$ and 0.003 , respectively). NAC involvement was more likely in Estrogen receptor (ER) and Progesterone receptor (PR) patients than in ER+ and PR+ patients $(p=0.000)$, while Human epidermal receptor (HER+) patients were more likely to have NAC involvement than HER patients $(p=0.000)$. Additionally, stage III cancer was significantly associated with NAC involvement $(p=0.041)$, and histological grade III disease carried a greater risk than grade I disease of NAC involvement ( $p=0.008)$.

Conclusion: The incidence of NAC affection among breast carcinoma patients who underwent mastectomy and axillary clearance was associated with important parameters, such as tumor size, areola edge-tumor distance, lymph node affection, hormonal receptor status and lymphovascular invasion. Accordingly, NAC-preserving surgeries could be tailored to patients with favourable tumor characteristics.
\end{abstract}

Keywords: Nipple-sparing mastectomy, NAC, Breast cancer

\footnotetext{
*Correspondence: M.faisal@med.suez.edu.eg; m.faisal@med.suez.edu.eg

'Surgical Oncology Unit, Department of Surgery, Faculty of Medicine, Suez

Canal University Hospital, Circular Road, Ismailia 411522, Egypt

Full list of author information is available at the end of the article
}

(C) The Author(s). 2019 Open Access This article is distributed under the terms of the Creative Commons Attribution 4.0 International License (http://creativecommons.org/licenses/by/4.0/), which permits unrestricted use, distribution, and reproduction in any medium, provided you give appropriate credit to the original author(s) and the source, provide a link to the Creative Commons license, and indicate if changes were made. The Creative Commons Public Domain Dedication waiver (http://creativecommons.org/publicdomain/zero/1.0/) applies to the data made available in this article, unless otherwise stated. 


\section{Introduction}

There has been significant progress in the operative management of breast carcinoma within the last six decades, as demonstrated by the adoption of conservative breast cancer surgery with great enhancements in early and delayed breast reconstruction surgery into skin-sparing mastectomy, which maintains an original skin cover and has already gained broad approval $[1,2]$.

Despite this progress, conventional skin-sparing mastectomy forfeits both the nipple and the areola, which serve as a focus of the breast [2]. The nipple-areola complex (NAC) provides unique character because many women believe that their own breast renovation is not complete until the nipple is reassembled [3]. Nonetheless, nipple renovation rarely provides patient satisfaction because of insufficient projection, colour, form, sizing, texture, consistency and posture $[4,5]$.

Nonetheless, nipple renovation rarely provides patient satisfaction because of insufficient projection, colour, form, sizing, texture and consistency and posture [6].Also Nipple reconstruction is at risk of tissue necrosis as the tissue becomes critically ischemic when raised off the skin blood supply. Skin perfusion is related to microcirculation [7] As such, nipple-sparing mastectomy (NSM) has gained consideration for the purpose of achieving 3 main targets: first, oncological safety; second, nipple-areola viability; and third, improved outcome [8]. By far, the most crucial of these aims is to achieve oncological safety because the nipple is linked to the mammary gland through lactiferous ducts and is likely at risk for malignant locoregional recurrence.

Recent multivariate models that can help the selection of patients eligible for NSM have revealed the following predictors of occult nipple involvement: tumour size, tumour location and tumour-nipple distance [9].

\section{Patients and methods Study design}

A retrospective observational study that took place at the Surgical Oncology Unit of the Department of Surgery, Suez Canal University Hospital, from June 15, 2014 to January 25, 2017 assessing the prevalence of malignant affection of the nipple-areola complex (NAC) in breast carcinoma patients and its correlation with prognostic factors for breast cancer. This research project has been approved by the research ethics committee of the Faculty of Medicine, Suez Canal University (reference number \#1890.

\section{Study population}

The study included One hundred thirty-seven (137) women with a diagnosis of operable breast cancer who underwent modified radical mastectomy. We excluded patients with clinical involvement of the NAC, such as Paget's disease, fixed nipple, and nipple erosion or induration, scheduled for other simultaneous procedure, had recurrent breast cancer patient, with previous radiation over chest wall, who cannot understand or cannot accept the study (refused to sign written informed consent) or patient unfit for surgery. Written consent was obtained from all patients.

\section{Study hypothesis}

We hypothesized that nipple- sparing mastectomy can be performed in certain selected patients with oncological safety and better cosmetic outcome.

\section{Study outcome}

- The primary outcome was to identify the subtle group of patients whom will have a privilege of NAC-sparing mastectomy.

- The secondary outcome of this study was to correlate between NAC involvement and certain tumor factors including tumor size, tumor-NAC distance, histological type, nuclear grade of the tumor and axillary lymph node status.

\section{Preoperative workup and surgical procedure}

All patients provided a full history and underwent general and local clinical examinations, pre-operative laboratory tests, and radiological and pathological evaluations, pre-operative needle biopsy, either fine-needle aspiration biopsy (FNAB) or Tru-Cut core needle biopsy guided by ultrasonography.

\section{Study intervention and surgical procedure}

The nipple and areola were segregated from the breast tissue and then sectioned at 5-mm intervals from the core of the nipple to the edge. Each section was further sectioned at $2.5 \mathrm{~mm}$ and embedded for assessment of its entirety. Specimens were examined histopathologically, as follow: Tumor size, type, and grade, Lymph node involvement, number of involved lymph nodes, tumor stage, and NAC involvement, as indicated by malignant cells. Malignant NAC involvement was examined in detail, including in terms of the distance from the periphery of the main tumour. All patients enrolled in this study were managed by modified radical mastectomy. The breast tissue was removed, and formal axillary lymph node dissection was performed through an elliptical incision encompassing the NAC. All breast tissue and axillary lymph nodes were removed en bloc, followed by histopathological examination.

\section{Statistical analysis}

SPSS version 20 (IBM) was used for the data analysis; 95\% confidence intervals (CIs) were calculated, and $p$ values $<0.05$ were considered statistically significant. 
Data. Mann Whitney was used for non-normally distributed data of quantitative variables. Fischer exact test was used to compare between data of qualitative nominal variables. Wilcoxon sign test was used compare between data of qualitative categorical variables. Relative Risks (RRs) with 95\% confidence intervals (CIs) had been estimated from the novel publications. To measure the pooled RRs with 95\% CIs, fixed-effect model was used when there was minimal heterogeneity in the variables among studies and random-effect-model when significant heterogeneity. Between-study, chi-square test was used for presenting heterogeneity of RR. Chi Square test was considered significant if $\mathrm{p}<0.05$. ROC curve analysis was performed to identify a cut-off value for the tumour-nipple distance associated with NAC involvement.

\section{Results}

In the present study, 137 female patients with breast cancer were included. They were classified after mastectomy into 2 subgroups according to NAC involvement. Demographic and clinicopathological data for all patients are shown in Table 1. The upper outer compartment was the most common tumor site in all patients $(37.2 \%)$. Regarding histopathology, the most common type of all recruited patients was invasive ductal carcinoma (IDC, 75.2\%), followed by infiltrating lobular carcinoma (ILC, 24.2\%), with $46 \%$ of the patients having histological grade I disease. Lymph node involvement was present in $28.5 \%$ of all patients. Stage II disease was present in the majority of cases (58.4\%). Lymphovascular invasion was revealed in $15.3 \%$ of the patients Fig 1.

While comparing the subgroups regarding age revealed no significant differences, patients with NAC involvement showed significantly larger tumors and shorter tumor-nipple distances than patients without NAC involvement. There was no difference in the tumor site between the subgroups. There were no significant differences between the subgroups regarding the histological type; however, regarding the histological grade, grade III disease was significantly more frequent among the patients with NAC involvement.

Lymph node involvement was significantly more common in the NAC group, as more than 10 lymph nodes were excised from approximately $89 \%$ of patients in this subgroup compared to $13.3 \%$ of patients in the other subgroup. Stage III disease was found in $72.7 \%$ of patients with NAC involvement compared to $38.9 \%$ of patients without NAC involvement $(p=0.032)$. Multicentric and multifocal tumors were detected significantly more frequently among patients with NAC involvement ( $p=0.016$ and 0.003 , respectively), as was lymphovascular invasion, which was found in $41.7 \%$ of patients with NAC involvement compared to $12.8 \%$ of patients without NAC involvement. A significant number of patients with NAC involvement were ER- and PR-, but a higher percentage of patients in this group than in the other group were HER+.

Age was not a significant predictor of NAC involvement. The risk of NAC increased with tumor sizes $\geq 4$ $\mathrm{cm}$ compared to tumor sizes $<4 \mathrm{~cm}(\mathrm{RR}=6.92, p=$ 0.003). Tumor-nipple distances $<2 \mathrm{~cm}$ versus $>2 \mathrm{~cm}$ and $<2.5 \mathrm{~cm}$ versus $>2.5 \mathrm{~cm}$ carried a greater risk of NAC involvement Relative Risk (RR) $=0.029$ and 0.019; $p=0.002$ and 0.004 , respectively) Table 2 .

Lymph node metastasis was associated with NAC involvement $(\mathrm{RR}=9.5 ; p=0.001)$, with increased risk when more than 10 lymph nodes were involved $(R R=26$; $p=0.007)$. Lymphovascular invasion was a significant predictor of NAC involvement $(\mathrm{RR}=4.86 ; p=0.014)$. Multifocal $(\mathrm{RR}=6.44 ; p=0.008)$ and multicentric $(\mathrm{RR}=9.5 ; \mathrm{p}=$ 0.001 ) tumors were significantly associated with NAC involvement Table 2.

ER- patients had a higher risk for NAC involvement than $\mathrm{ER}+$ patients $(\mathrm{RR}=16.85 ; p<0.001)$. Additionally, PR- patients had a higher risk for NAC involvement than $\mathrm{PR}+$ patients $(\mathrm{RR}=33.6 ; \mathrm{p}<0.001)$ Table 2 .

HER + patients were more likely to have NAC involvement than HER- patients $(R R=16.0 ; p<0.001)$. Stage III cancer was significantly associated with NAC involvement compared to stage II cancer $(\mathrm{RR}=4.19 ; p=0.041)$ Table 2.

Both histopathological types identified were considered non-predictors for NAC; however, histological grade III disease carried a greater risk than grade I disease of developing NAC involvement $(\mathrm{RR}=9.03$; $p=$ 0.008). Additionally, histological grade III disease carried a greater risk than grade II disease of developing NAC involvement $(\mathrm{RR}=5.48 ; p=0.040)$ Table 2 .

ROC curve analysis was performed to identify a cut-off value for the tumor-nipple distance associated with NAC involvement; a tumor-nipple distance of 2.4 $\mathrm{cm}$ had a sensitivity and specificity of 83 and 68\%, respectively ( $\mathrm{AUC}=0.775 ; p=0.002)$ Fig. 2 .

\section{Discussion}

NAC resection was previously included in the surgical management of breast carcinoma. This was done regarding the evidence of accumulated lymphatic drainage of the breast into the subareolar Sappey plexus before eventually draining into the axillary lymph nodes [10]. Turner-Warwick had discarded the previous theory and demonstrated that lymphatic vessels accompany blood vessels in the breast tissue leaving the nipple area [11]. To clarify this discrepancy, we postulated that Sappey's original studies included lactating but not resting breasts [12].

In this analysis, we studied surgical specimens from 137 females who had undergone mastectomy. Of all the examined specimens, $12 \quad(8.7 \%)$ showed tumour 
Table 1 Demographic and clinicopathologic data of all patients

\begin{tabular}{|c|c|c|c|c|c|}
\hline & & All patients & $\begin{array}{l}\text { Patients with NAC } \\
N=12\end{array}$ & $\begin{array}{l}\text { Patients without NAC } \\
N=125\end{array}$ & $p$-value \\
\hline \multirow[t]{2}{*}{ Age } & & $47.39 \pm 8.01$ & $50.9 \pm 6.8$ & $47.1 \pm 8.1$ & $0.136^{a}$ \\
\hline & & $32-58$ & & & \\
\hline \multirow[t]{3}{*}{ Age subgroups } & $30-39$ & $35(25.5)$ & $2(16.7)$ & $33(26.4)$ & $0.686^{b}$ \\
\hline & $40-49$ & $37(27)$ & $3(25)$ & $34(27.2)$ & \\
\hline & $\geq 50$ & $65(47.4)$ & $7(58.3)$ & $58(46.4)$ & \\
\hline Tumor size & & $2.9 \pm 1.16$ & $4.18 \pm 1.16$ & $2.35 \pm 1.1$ & $<0.001^{\mathrm{a}}$ \\
\hline Range & & $1-6$ & & & \\
\hline$<4 \mathrm{~cm}$ & & $101(73.7)$ & $4(33.3)$ & $97(77.6)$ & $0.003^{b}$ \\
\hline$\geq 4 \mathrm{~cm}$ & & $36(26.3)$ & $8(66.7)$ & $28(22.4)$ & \\
\hline Tumor nipple distance & & $3.38 \pm 0.92$ & $1.95 \pm 0.72$ & $3.52 \pm 0.84$ & $<0.001^{\mathrm{a}}$ \\
\hline Range & & $1.4-6$ & & & \\
\hline$<2 \mathrm{~cm}$ & & $6(4.4)$ & $4(33.3)$ & $2(1.6)$ & $<0.001^{a}$ \\
\hline $2-<2.5 \mathrm{~cm}$ & & $11(8)$ & $2(16.7)$ & $9(7.2)$ & \\
\hline $2.5-<3 \mathrm{~cm}$ & & $4(2.9)$ & $3(25)$ & $1(0.8)$ & \\
\hline $3-<4 \mathrm{~cm}$ & & 79 (57.7) & $1(8.3)$ & $78(62.4)$ & \\
\hline$\geq 4 \mathrm{~cm}$ & & $37(27)$ & $2(16.7)$ & $35(28)$ & \\
\hline \multirow[t]{5}{*}{ Tumor site } & Upper inner & $22(16.1)$ & $1(8.3)$ & $21(16.8)$ & $0.470^{b}$ \\
\hline & Upper outer & $26(19.1)$ & $2(16.7)$ & $24(19.2)$ & \\
\hline & Lower inner & $31(22.6)$ & $1(8.3)$ & $30(24)$ & \\
\hline & Lower outer & $7(5.1)$ & $1(8.3)$ & $6(4.8)$ & \\
\hline & Central & $51(37.2)$ & $7(58.3)$ & $44(35.2)$ & \\
\hline \multirow[t]{4}{*}{ Histologic type } & DCIS & $32(23.4)$ & $5(41.7)$ & 27 (21.6) & $0.033^{b}$ \\
\hline & IDC & $37(27)$ & $5(41.7)$ & $32(25.6)$ & \\
\hline & LCIS & $43(31.4)$ & $1(8.3)$ & $42(33.6)$ & \\
\hline & ILC & $25(18.2)$ & $1(8.3)$ & $24(19.2)$ & \\
\hline \multirow[t]{3}{*}{ histologic grade } & Grade I & $63(46)$ & $2(16.7)$ & $61(48.8)$ & $0.003^{b}$ \\
\hline & Grade II & $39(28.5)$ & $2(16.7)$ & $37(29.6)$ & \\
\hline & Grade III & $35(25.5)$ & $8(66.7)$ & 27 (21.6) & \\
\hline Lymph node involvement & Positive & $39(28.5)$ & $9(75)$ & $30(24)$ & $0.001^{\mathrm{b}}$ \\
\hline \multirow[t]{3}{*}{ Lymph node numbers } & $<4$ & $13(9.5)$ & $0(8.3)$ & $13(43.3)$ & $<0.001^{a}$ \\
\hline & $4-<10$ & $14(10.2)$ & $1(11.1)$ & $13(43.3)$ & \\
\hline & $\geq 10$ & $12(8.8)$ & $8(88.9)$ & $4(13.3)$ & \\
\hline \multirow[t]{2}{*}{ Staging } & $\|$ & $80(58.4)$ & $3(27.3)$ & 77 (61.6) & $0.032^{b}$ \\
\hline & III & $57(41.6)$ & $8(72.7)$ & 49 (38.9) & \\
\hline Multifocal tumor & & $13(9.5)$ & $4(33.3)$ & $9(7.2)$ & $0.016^{b}$ \\
\hline Multicenteric & & $14(10.2)$ & $5(41.7)$ & $9(7.2)$ & $0.003^{b}$ \\
\hline Lymphovascular invasion & & $21(15.3)$ & $5(41.7)$ & $16(12.8)$ & $0.020^{b}$ \\
\hline Estrogen receptor status & & $13(9.5)$ & $6(50)$ & $7(5.6)$ & $<0.001^{b}$ \\
\hline Progesterone receptor status & & $12(8.8)$ & $7(58.3)$ & $5(4)$ & $<0.001^{\mathrm{b}}$ \\
\hline HER status & & $17(12.4)$ & $7(58.3)$ & $10(8)$ & $<0.001^{b}$ \\
\hline
\end{tabular}

${ }^{a}$ :Mann Whitney test ${ }^{b}$ : Fischer exact test ${ }^{a}$ : Wilcoxon sign test 


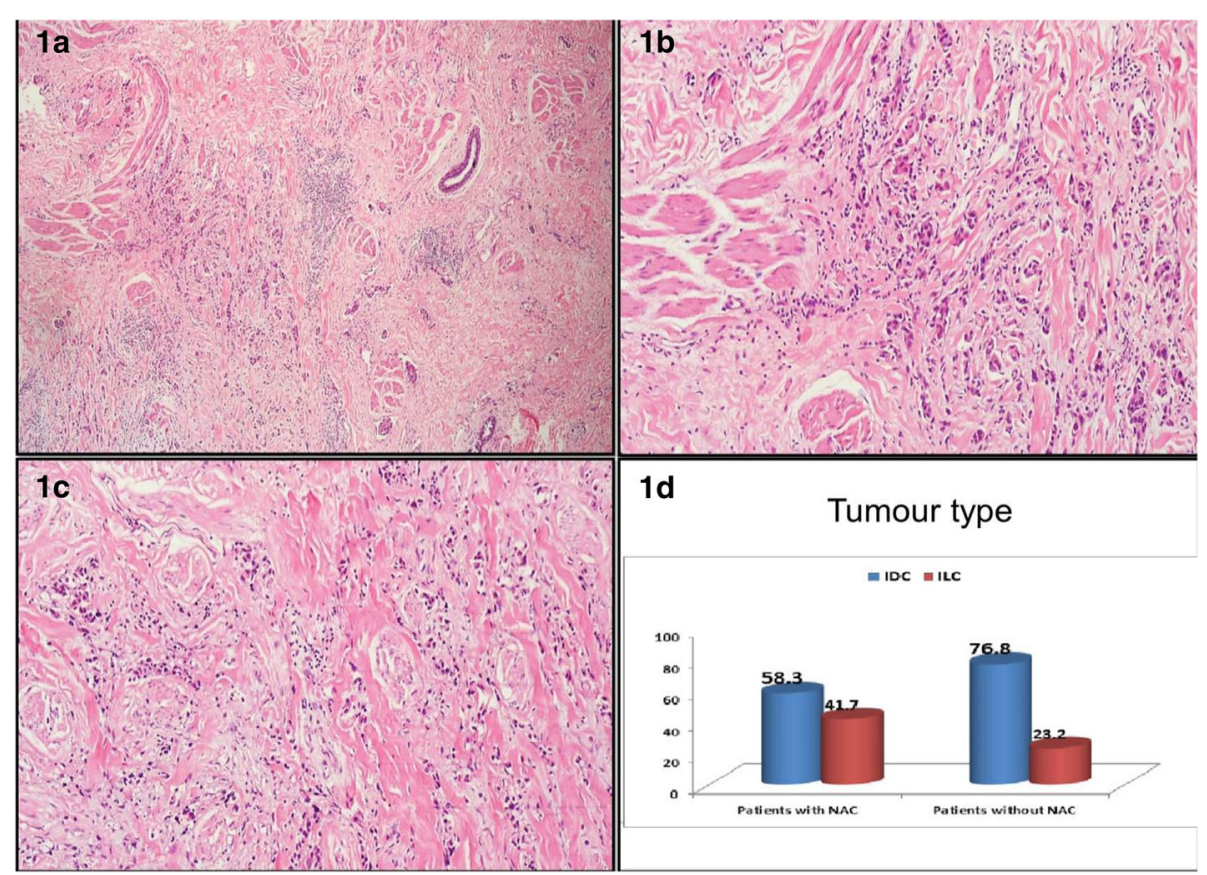

Fig. 1 Invasive ductal carcinoma of no special type surrounding the smooth muscle bundles of the nipple-areola complex (100X) (a). Higher magnification of (a) (200X) (b). Invasive lobular carcinoma surrounding the smooth muscle bundles of the nipple-areola complex (100X) (c). Distribution of the tumour types included in the study in relation to nipple-areola complex involvement (d)

Table 2 Predictors of NAC involvement

\begin{tabular}{|c|c|c|c|c|c|c|}
\hline & & \multirow[t]{2}{*}{ RR } & \multicolumn{2}{|c|}{$\mathrm{Cl}(95 \%)$} & \multirow[t]{2}{*}{ Wald } & \multirow[t]{2}{*}{$p$-value } \\
\hline & & & Lower & upper & & \\
\hline \multirow[t]{2}{*}{ Age subgroups } & $<40$ versus $>40$ years & 1.99 & 0.391 & 10.14 & 0.687 & 0.407 \\
\hline & $>40$ versus $>50$ years & 1.36 & 0.332 & 5.64 & 0.188 & 0.665 \\
\hline $\begin{array}{l}\text { Tumor size } \\
<4 \text { versus } \geq 4 \mathrm{~cm}\end{array}$ & & 6.92 & 1.94 & 24.17 & 8.89 & 0.003 \\
\hline \multirow{4}{*}{$\begin{array}{l}\text { Tumor nipple distance } \\
<3 \mathrm{~cm}\end{array}$} & $<2$ versus $>2 \mathrm{~cm}$ & 0.029 & 0.003 & 0.262 & 9.88 & 0.002 \\
\hline & $<2.5$ versus $>2.5 \mathrm{~cm}$ & 0.019 & 0.001 & 0.276 & 8.42 & 0.004 \\
\hline & $<3$ versus $>3 \mathrm{~cm}$ & 0.257 & 0.032 & 2.08 & 1.61 & 0.203 \\
\hline & $<4$ versus $>4 \mathrm{~cm}$ & 4.45 & 0.391 & 50.79 & 1.44 & 0.229 \\
\hline \multirow[t]{2}{*}{ Lymph node metastasis } & Metastasis versus no metastasis & 9.5 & 2.41 & 37.37 & 10.37 & $<0.001$ \\
\hline & $\geq 10$ versus $<10$ & 26.00 & 2.45 & 275.82 & 7.31 & 0.007 \\
\hline Multifocal tumor & Multifocal versus not multifocal & 6.44 & 1.62 & 25.58 & 7.01 & 0.008 \\
\hline Multicenteric & Multicentric versus not multicentric & 9.20 & 2.42 & 34.91 & 10.65 & $<0.001$ \\
\hline Lymphovascular invasion & Invasion versus noninvasion & 4.86 & 1.37 & 17.18 & 6.04 & 0.014 \\
\hline Estrogen receptor status & ER - versus ER+ & 16.85 & 4.30 & 65.97 & 16.46 & $<0.001$ \\
\hline Progesterone receptor status & PR - versus PR+ & 33.60 & 7.84 & 143.97 & 22.40 & $<0.001$ \\
\hline HER status & HER + versus HER - & 16.0 & 4.31 & 60.09 & 17.10 & $<0.001$ \\
\hline Staging III & Stage III versus II & 4.19 & 1.1 & 16.56 & 4.17 & 0.041 \\
\hline \multirow[t]{3}{*}{ Histologic tumor type } & DCIS versus ILC & 0.225 & 0.025 & 2.06 & 1.74 & 0.187 \\
\hline & DCIS versus IDC & 0.267 & 0.029 & 2.43 & 1.37 & 0.241 \\
\hline & IDC versus ILC & 1.75 & 0.105 & 29.26 & 0.152 & 0.697 \\
\hline \multirow[t]{2}{*}{ Histologic grade } & Grade III versus grade I & 9.03 & 1.79 & 45.40 & 7.14 & 0.008 \\
\hline & Grade III versus grade ॥ & 5.48 & 1.07 & 27.89 & 4.20 & 0.040 \\
\hline
\end{tabular}




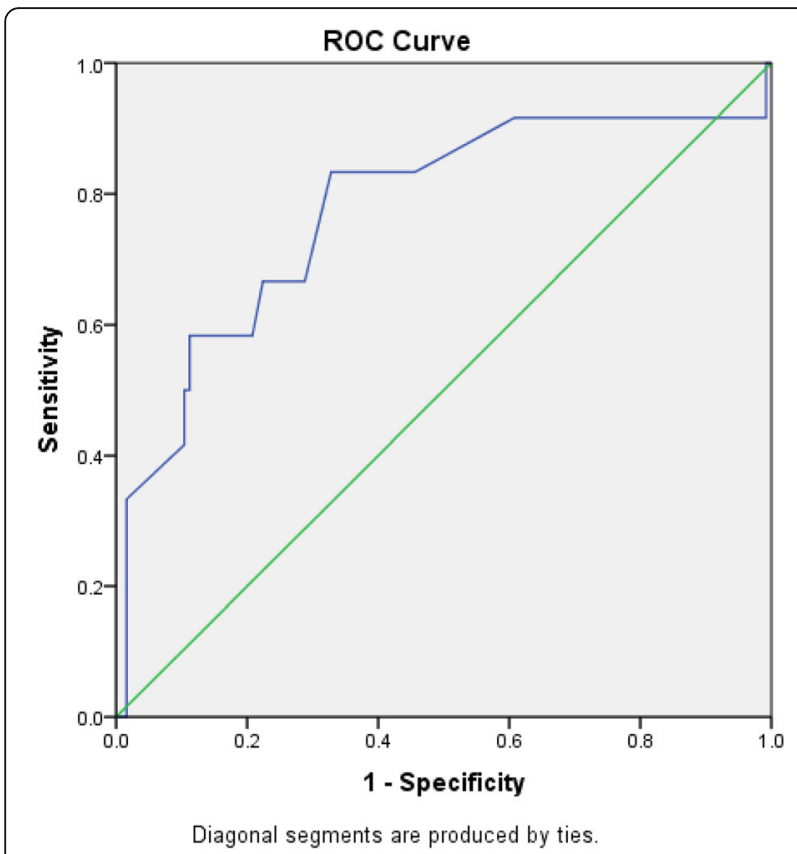

Fig. 2 ROC curve, cutoff value of tumor nipple distance for detecting NAC

involvement in the NAC. Six decades ago, some authors reported rates of tumor involvement in the NAC higher than that found in this study [13-15]. A relatively high rate of NAC involvement was also documented in a study by Pirozzi et al. [16]; however, only 50 women were enrolled in their study. Another study reported only 22 cases $(16 \%)$ of NAC involvement [17]. A small Libyan study documented NAC involvement in only 3 (12\%) out of 25 cases [18], which is similar to the figure reported by Crowseet et al. [19], while an Egyptian study demonstrated an incidence rate of $6.3 \%$ [20]. Incidence rates of nipple involvement (NI) ranging from 0 to $58 \%$ have been reported recently [21]; however, that study did not include the areola in the analysis. The anatomical difference between the areola and nipple is that the areola does not contain parenchymal ducts; on the other hand, the nipple has a lining of ductal cells; any of those cells could potentially produce breast cancer.

Many women prefer to preserve the nipple after mastectomy for a better cosmetic outcome. For this reason, multiple studies, including ours, have investigated the differences between breast cancer patients with and without NAC involvement and demonstrated the predictors of NAC involvement to enable the selection of patients who may be candidates for NAC preservation while maintaining oncological safety; however, other studies have shown discrepancies regarding the predictive factors.

In our study, we detected significantly larger tumours with shorter tumour-nipple distances in patients with NAC involvement than in patients without NAC involvement. Patients with a tumour-nipple distance $\leq 2.5 \mathrm{~cm}$ were more likely to have NAC involvement than patients with longer distances; additionally, patients with a tumour size $\geq 4 \mathrm{~cm}$ were at risk for NAC involvement $(p=0.003)$. A large meta-analysis by Zhang et al. reported that tumour-to-nipple distances $\geq 2.5 \mathrm{~cm}$ were associated with a reduced risk of NI [22]. Other reports have confirmed this distance regarding NI [17, 23]. Although another study comparing 2 groups regarding NAC involvement revealed no difference according to the tumor-nipple distance $(p=0.735)$, in the same study, when a dichotomous division of the distance was analysed, a distance $\leq 3 \mathrm{~cm}$ was detected in $100 \%$ of cases with NAC involvement compared to $60.5 \%$ of cases without NAC involvement $(p=0.007)$ [16]. This finding also agrees with the data reported by Bishop et al. [24]. A tumour size of more than $5 \mathrm{~cm}$ carried an increased risk for NI in a study by Wang et al. [25]. Pirozzi and his colleagues reported findings consistent with our results with respect to tumour size, as they found no differences between the two studied groups regarding NI when they categorized tumour size as $<3$ or $\geq 3 \mathrm{~cm}(p=0.693)$ [16].

With respect to lymph node metastasis in our analysis, we found a significantly higher rate of lymph node involvement among patients with NAC involvement than those without NAC involvement $(9(75 \%)$ versus $30(24 \%)$, respectively, $p=0.001)$. Additionally, lymphovascular invasion was more prevalent in patients with than in those without NAC involvement (5(41.7\%) vs. 16 (12.8\%), respectively). Mallon et al. described that nodal involvement was a valuable predictor of NAC involvement [26]; however, another report revealed contrasting results [27], in which a higher nodal stage was not associated with NI. The results reported by Wang et al. agree with our findings, as they demonstrated that nodal involvement was associated with NAC involvement (NAC involvement in $14 \%$ of tumours positive for nodal involvement vs. $8 \%$ in tumour negative for nodal involvement, $p=0.0331$ ) [25].

Despite lymphovascular invasion being an important predictor of increased tumour aggressiveness, the data published by Pirozzi et al. revealed that lymphovascular invasion was detected in 15 of the 50 cases studied; of those patients, 14 did not show NI, and only 1 showed NI. Comparing the two groups showed no significant difference [16]. The previous results were in contrast with those revealed by Vyas et al. [17] and Vlajcic et al. [28], probably owing to the small sample size included in the current study.

Regarding the histological type among our cases, we detected that among all patients, as well as patients with NAC involvement, there was a predominance of IDC over ILC; however, there was no significant 
difference $(p=0.171)$. Additionally, none of the detected pathological types were significant predictors of NAC involvement ( $p=0.167)$. However, the histological grade was considered a significant predictor of NAC involvement among our cases, as $8(66.7 \%)$ of the patients with NAC involvement had grade 3 tumors.

Multiple studies have suggested that NI is associated mainly with ductal carcinoma in situ (DCIS) [23, 2931]. Li et al. [32] demonstrated that IDC or IDC with associated DCIS and breast carcinoma with invasive micropapillary carcinoma (IMPC) components were the most common tumour types associated with NI. Contrasting results regarding the histological grade were reported by Pirozzi et al., as they found no significant difference among groups regarding the histological grade [16]. Other studies have suggested that lobular carcinoma in situ (LCIS) is strongly associated with NI [33], although others have reported a negative association between LCIS and NI [34], as LCIS is not considered a true tumor lesion and does not require an additional safety margin when present at the surgical margin [35].

In our study, there was no significant difference in the tumor site between the groups, meaning that no specific region was associated with NAC involvement. Multiple studies have shown that the tumor location is an important predictor of NAC involvement [12, 36, 37]. This discrepancy could be attributed to the relatively small sample size, which is also reflected in the relatively low positive rate of NAC involvement.

In our study, $6(50 \%)$ of patients with NAC involvement were ER-, while 7(58.3\%) of patients with NAC involvement were PR- and HER+. A systematic review by Zhang et al. reported a higher rate of NI among ER- patients (1.189, 95\% $\mathrm{CI}=1.008-1.404)$ and PR- patients $(1.515,95 \% \mathrm{CI}=1.248$ 1.84). On the other hand, the pooled analysis of the same study with respect to HER status revealed a stronger association between having NI and being HER+ ( RR $=1.760,95 \%$ $\mathrm{CI}=1.463-2.116)$ [22]. Another study reported that HER overexpression was associated with NAC involvement $(p=$ 0.0137), which supports our findings [25]. Brachtel et al. have also reported that HER2 overexpression is associated with NAC involvement [31]. HER positivity in patients with NAC involvement may be a potential indicator of the presence of Paget's disease. Pirozzi and his colleagues published different results regarding hormonal factors, as they found no significant differences between the groups described in this study regarding PR and ER status $(p=0.794$ and 0.825 , respectively) [16].

\section{Conclusion}

The incidence of NAC involvement among patients with breast carcinoma who underwent mastectomy and axillary clearance was associated with certain important factors, such as the tumour size, the distance from the tumour site to the edge of the areola, lymph node metastasis, lymphovascular invasion, HER overexpression, and ER and PR negativity. Accordingly, NAC-preserving surgeries and NSM are oncologically safe procedures in well selected patients with tumors at stages 0-II, peripheral tumors far from the nipple, and with favourable pathological features.

\section{Abbreviations \\ Cl: Confidence Incidence; DCIS: Ductal carcinoma in situ; ER: Estrogen receptor; HER: Human epidermal receptor; LBCI: Lobular carcinoma in situ; NAC: Nipple Areola Complex; NI: Nipple Involvement; NSM: Nipple sparing mastectomy; PR: Progesterone receptor; RR: Relative Risk}

\section{Acknowledgements \\ The authors would like to thank Dr. Ahmed Abdallah, MSc, for his helpful supervision of the statistical analysis.}

\section{Funding}

The authors declare that no funding from any sources has been received for this work.

\section{Availability of data and materials}

The datasets utilized and/or analysed in this study are accessible from the corresponding author upon reasonable request. All data provided or analysed during this study are involved in this published article [and its supplementary information files].

\section{Authors' contributions}

MF performed the surgery, participated in the study design and the study alignment, and drafted the manuscript and final revision. HF performed the surgical procedures, participated in the data acquisition, sequence alignment and study design, and contributed to the coordination and final revision of the manuscript. AG performed the surgical procedures and reviewed and proofread the article. HA participated in designing the study and surgery and helped performed the statistical analysis and draft the manuscript. MS helped design the study and coordinate and critically revise the manuscript. MA performed the histopathological assessment and helped draft and prepare the final manuscript. All authors revised and accepted the final draft for submission.

\section{Ethics approval and consent to participate}

Our study was approved by the research ethics committee of the Faculty of Medicine, Suez Canal University, at its meeting on 23/02/2014 (reference number \#1937).

\section{Consent for publication}

We have obtained consent to publish case reports through our institutional consent form.

\section{Competing interests}

The authors declare that they have no competing interests.

\section{Publisher's Note}

Springer Nature remains neutral with regard to jurisdictional claims in published maps and institutional affiliations.

\section{Author details}

${ }^{1}$ Surgical Oncology Unit, Department of Surgery, Faculty of Medicine, Suez Canal University Hospital, Circular Road, Ismailia 411522, Egypt. ${ }^{2}$ Department of Pathology, Faculty of Medicine, Suez Canal University, Ismailia, Egypt.

Received: 5 December 2018 Accepted: 25 February 2019

Published online: 16 March 2019

References

1. Warren Peled A, Foster RD, Stover AC, Itakura K, Ewing CA, Alvarado M, et al. Outcomes after total skin-sparing mastectomy and immediate reconstruction in 657 breasts. Ann Surg Oncol. 2012;19:3402-9. 
2. Rossi C, Mingozzi M, Curcio A, Buggi F, Folli S. Nipple areola complex sparing mastectomy. Gland Surg. 2015;4:528-40.

3. Nimboriboonporn A, Chuthapisith S. Nipple-areola complex reconstruction. Gland Surg. 2014;3:35-42.

4. Jabor MA, Shayani P, Collins DR, Karas T, Cohen BE. Nipple-areola reconstruction: satisfaction and clinical determinants. Plast Reconstr Surg. 2002;110:457-63 discussion 464-465.

5. Andrade WN, Baxter N, Semple JL. Clinical determinants of patient satisfaction with breast reconstruction. Plast Reconstr Surg. 2001;107:46-54

6. Didier F, Radice D, Gandini S, Bedolis R, Rotmensz N, Maldifassi A, et al. Does nipple preservation in mastectomy improve satisfaction with cosmetic results, psychological adjustment, body image and sexuality? Breast Cancer Res Treat. 2009;118:623-33.

7. Sisti A, Grimaldi L, Tassinari J, Cuomo R, Fortezza L, Bocchiotti MA, et al. Nipple-areola complex reconstruction techniques: A literature review. Eur J Surg Oncol EJSO. 2016;42:441-65.

8. Rusby JE, Smith BL, Gui GPH. Nipple-sparing mastectomy. Br J Surg. 2010;97:305-16.

9. Dieterich M, Gerber B. Patient selection and technical considerations in nipple-sparing and areola-sparing mastectomy. Curr Breast Cancer Rep. 2011;3:79-87.

10. Suami H, Pan W-R, Mann GB, Taylor Gl. The Lymphatic Anatomy of the Breast and its Implications for Sentinel Lymph Node Biopsy: A Human Cadaver Study. Annals of Surgical Oncology. 2008;15(3):863-71.

11. Turner-Warwick RT. The lymphatics of the breast. Br J Surg. 1959;46:574-82.

12. Cense HA, Rutgers ET, Cardozo ML, Van Lanschot JJB. Nipple-sparing mastectomy in breast cancer: a viable option? Eur J Surg Oncol EJSO. 2001; 27:521-6.

13. Lagios MD, Gates EA, Westdahl PR, Richards V, Alpert BS. A guide to the frequency of nipple involvement in breast cancer. Am J Surg. 1979; 138:135-42

14. Smith J, Payne WS, Carney JA. Involvement of the nipple and areola in carcinoma of the breast. Surg Gynecol Obstet. 1976;143:546-8.

15. Andersen JA, Pallesen RM. Spread to the nipple and areola in carcinoma of the breast. Ann Surg. 1979;189:367.

16. Pirozzi PR, Rossetti C, Carelli I, Ruiz CA, Pompei LM, Piato S. Clinical and morphological factors predictive of occult involvement of the nipple-areola complex in mastectomy specimens. Eur J Obstet Gynecol Reprod Biol. 2010; 148:177-81.

17. Vyas JJ, Chinoy RF, Vaidya JS. Prediction of nipple and areola involvement in breast cancer. Eur J Surg Oncol EJSO. 1998;24:15-6.

18. Abdallah FA, Stephen J, Martynyuk A, Musa MF, Mohamed AM, Bakkar MY. Evaluation of Nipple-Areola Complex (NAC) involvement in Breast Carcinoma. Sebha Medical Journal. 2013:12(1):37-42.

19. Crowe JP Jr, Kim JA, Yetman R, Banbury J, Patrick RJ, Baynes D. Nipplesparing mastectomy: technique and results of 54 procedures. Arch Surg. 2004;139:148-50.

20. Afifi RY, El-Hindawy A. Analysis of nipple-areolar complex involvement with mastectomy: can the nipple be preserved in Egyptian patients receiving skin-sparing mastectomy? Breast J. 2004;10:543-5.

21. Gomez C, Shah C, McCloskey S, Foster N, Vicini F. The role of radiation therapy after nipple-sparing mastectomy. Ann Surg Oncol. 2014;21:2237-44.

22. Zhang H, Li Y, Moran MS, Haffty BG, Yang Q. Predictive factors of nipple involvement in breast cancer: a systematic review and meta-analysis. Breast Cancer Res Treat. 2015:151:239-49.

23. Morimoto T, Komaki K, Inui K, Umemoto A, Yamamoto H, Harada K, et al. Involvement of nipple and areola in early breast cancer. Cancer. 1985;55: 2459-63.

24. Bishop CC, Singh S, Nash AG. Mastectomy and breast reconstruction preserving the nipple. Ann R Coll Surg Engl. 1990;72:87.

25. Wang J, Xiao X, Wang J, Iqbal N, Baxter L, Skinner KA, et al. Predictors of nipple-areolar complex involvement by breast carcinoma: histopathologic analysis of 787 consecutive therapeutic mastectomy specimens. Ann Surg Oncol. 2012;19:1174-80.

26. Mallon P, Feron J-G, Couturaud B, Fitoussi A, Lemasurier P, Guihard T, et al. The role of nipple-sparing mastectomy in breast cancer: a comprehensive review of the literature. Plast Reconstr Surg. 2013;131:969-84.

27. Banerjee A, Gupta S, Bhattacharya N. Preservation of nipple-areola complex in breast cancer-a clinicopathological assessment. J Plast Reconstr Aesthet Surg. 2008;61:1195-8.
28. Vlajcic Z, Zic R, Stanec S, Lambasa S, Petrovecki M, Stanec Z. Nipple-areola complex preservation: predictive factors of neoplastic nipple-areola complex invasion. Ann Plast Surg. 2005;55:240-4.

29. Wertheim U, Ozzello L. Neoplastic involvement of nipple and skin flap in carcinoma of the breast. Am J Surg Pathol. 1980;4:543-9.

30. Menon RS, Van Geel AN. Cancer of the breast with nipple involvement. Br J Cancer. 1989;59:81.

31. Brachtel EF, Rusby JE, Michaelson JS, Chen LL, Muzikansky A, Smith BL, et al. Occult nipple involvement in breast cancer: clinicopathologic findings in 316 consecutive mastectomy specimens. J Clin Oncol. 2009;27:4948-54.

32. Li W, Wang S, Guo X, Lang R, Fan Y, Gu F, et al. Nipple involvement in breast cancer: retrospective analysis of 2323 consecutive mastectomy specimens. Int J Surg Pathol. 2011;19:328-34.

33. Caruso F, Ferrara M, Castiglione G, Trombetta G, De Meo L, Catanuto G, et al. Nipple sparing subcutaneous mastectomy: sixty-six months follow-up. Eur J Surg Oncol. 2006;32:937-40.

34. D'Alonzo M, Martincich L, Biglia N, Pisacane A, Maggiorotto F, De Rosa G, et al. Clinical and radiological predictors of nipple-areola complex involvement in breast cancer patients. Eur J Cancer. 2012;48:2311-8.

35. Moran MS, Schnitt SJ, Giuliano AE, Harris JR, Khan SA, Horton J, et al. Society of Surgical Oncology-American Society for Radiation Oncology consensus guideline on margins for breast-conserving surgery with whole-breast irradiation in stages I and II invasive breast cancer. Int J Radiat Oncol Biol Phys. 2014;88:553-64.

36. Simmons RM, Brennan M, Christos P, King V, Osborne M. Analysis of nipple/ areolar involvement with mastectomy: can the areola be preserved? Ann Surg Oncol. 2002;9:165-8.

37. Laronga C, Kemp B, Johnston D, Robb GL, Singletary SE. The incidence of occult nipple-areola complex involvement in breast cancer patients receiving a skin-sparing mastectomy. Ann Surg Oncol. 1999;6:609-13.

\section{Ready to submit your research? Choose BMC and benefit from:}

- fast, convenient online submission

- thorough peer review by experienced researchers in your field

- rapid publication on acceptance

- support for research data, including large and complex data types

- gold Open Access which fosters wider collaboration and increased citations

- maximum visibility for your research: over $100 \mathrm{M}$ website views per year

At BMC, research is always in progress.

Learn more biomedcentral.com/submissions 